\title{
A Framework for Research and Practice: Relationship among Perception of Organizational Politics, Perceived Organization Support, Organizational Commitment and Work Engagements
}

\author{
Zhiliang Rong, Guiling Cao \\ School of Business Administration, South China University of Technology, Guangzhou, China \\ Email: chileungyung@foxmail.com
}

Received 22 September 2015; accepted 20 October 2015; published 23 October 2015

Copyright (C) 2015 by authors and Scientific Research Publishing Inc.

This work is licensed under the Creative Commons Attribution International License (CC BY). http://creativecommons.org/licenses/by/4.0/

(c) (i) Open Access

\section{Abstract}

Since the Reform and Opening-up in China, the rapid development of China's economy has lasted for nearly forty years. As the basic units of economic activity, Chinese enterprises also continue to grow. Especially in recent years, the enterprises have become increasingly scientific and standardized. However, the "Officer Standard", residual product of thousands of years of Chinese feudal society and the centralization consciousness in culture, leads to organizational polities existing in various organizations. Moreover, the inevitable contradiction between the scarcity of resources and the multiplicity of interests aggravates intrigue and calculation. As a subjective understanding and evaluation of the degree of Self-Interest behaviors of other people in the organization, perception of organizational politics has been proved to have an important impact on the attitude and behavior of employees. As a heated research topic of active organization behavior, work engagement may be affected by the perception of organizational politics of the staff, and has a profound influence on the organization's vitality and development. Based on the Chinese cultural background, this research theoretically studies the relationship among the perception of organizational politics, perceived organization support, organizational commitment and work engagement. We adopt the method of literature research and go over the related research results systematically. At the same time, we put forward the theoretical model of this study by employing Conservation of Resources theory and Social Exchange theory. Our research result has indicated that the perception of organizational politics is negatively related to work engagement, in which organizational commitment plays a mediating role and perceived organization support plays a regulating role. 
Keywords

\section{Perception of Organizational Politics, Perceived Organization Support, Organizational Commitment, Work Engagements}

\section{Introduction}

In management practice, because of the scarcity of the organization resources and the multiplicity of interests, the organization politics is filled in the every process of enterprise management. Burns proposed "micro politics" in 1961, which was regarded as opening a new chapter in the study of organizational politics by academic circles. He stated that organizational politics was a behavior that individual utilized organizational resources in order to obtain better working environment, stronger power and influence. These behaviors might generate adverse effects on organizational internal competition fairness [1]. Mayes and Allen (1977) thought that organizational politics was a social impact on the others so as to gain personal interests without recognition, which would influence organizational management order [2]. Other scholars believed that organizational politics would bring a positive impact to organizations. Kotter (1985) pointed out that organization politics was the necessary means to guide the organization change, and it was the main method to solve the conflict [3]. Then because of the difficulty to measure organizational politics accurately, the research achievements of organizational politics reduced suddenly. Therefore, more and more scholars transformed their research direction to the perception of organizational politics and made a breakthrough.

Perception belongs to the category of psychology. It is a process of selecting, organizing and explaining the information that people feel. Lewin (1936) indicated that people reacted to the perception of reality rather than the reality itself [4]. Different scholars had different opinions on the definition of the perception of organizational politics. Ferris and Kacmar (1992) thought that the perception of organizational politics was a subjective psychological process, which was the individual's perception of the political behavior of others [5]. Hochwarter, W. et al. (2000) believed that the perception of organizational politics was employees' perception and estimate of the activities to maximize self-benefit of individuals, groups, and organizations [6]. Ferris, G. et al. (2000) put forward the definition that the perception of organizational politics was subjective evaluation of degree of selfserving behavior of organization members in the working environment [7]. Ferris and Kacmar (1992) found that the perception of organizational politics could improve work engagements. They explained for the research result that when people realized the organizational politics, they would take some measures to avoid them and work with their total dedication [5]. Nevertheless, Cropanzano et al. (1997) made a opposite finding. They argued that the perception of organizational politics would cut down employees' work engagements. And they pointed out there was a premise of error about Ferris and Kacmar's research that they assumed that employees would stay on while feeling the organizational politics [8]. The outcome variables of perception of organizational politics could be divided into three categories, including psychology, attitude and behavior [9]. Scholars found that the perception of organizational politics was likely to decrease job satisfaction [10] [11], organizational commitment [10], work engagements [12], and to increase turnover intention [8] [13]. In general, most of the related researches showed that the perception of organizational politics would bring about negative effect [14]. However, in the academic field in China, attention had not been paid to organizational politics in Chinese business.

So far, research studying the perception of organizational politics has become matured gradually in Western countries. Most of researches on perception of organizational politics are based on western cultural background. A discussion is worthwhile whether present research results are still available in other cultural background. Moreover, present researches paid more attention on how perception of organizational politics directly influences on employees' work engagements and less attention to the internal mechanism between the two variables. We searched literatures by means of keyword searching method in CNKI and found that there were only 145 relevant researches about perception of organizational politics in China. Obviously, it is not enough to provide millions organizations in China with guidance significance. The progress of the research about perception of organizational politics in China lagged far behind Chinese economic development.

Hofstede (1980) pointed that national culture did influence employees' mental programs [15]. There were different evaluations and expectations on the social exchange relationship among the employees from different 
countries [16]. Consequently, as a subjective evaluation of degree of self-serving behavior of organization members, perception of organizational politics would be influenced by national culture. Therefore, it is necessary to consider the impact of different cultural background.

In the research, we were going to analyze the relationship among perception of organizational politics, organizational commitment and work engagements so as to explore how perception of organizational politics influences employees' work engagements. At the same time, we took employees' perceived organization support into our consideration and studied how perceived organization support played its role in our research framework. Hence, we theoretically discussed the relationship among four variables, including perception of organizational politics, perceived organization support, organizational commitment and work engagements.

\section{Method}

Scientific research must be based on a solid theoretical research. Therefore, sufficient analysis of the literature data is significant. We searched a large amount of literatures both in China and abroad from CNKI and Springer by keywords searching, including perception of organizational politics, perceived organization support, organizational commitment and work engagements to achieve purpose of our research. We started with summarizing and analyzing previous research results and come up with our research topic. With the support of theory, we put forward a hypothesis model with four variables, including perception of organizational politics, perceived organization support, organizational commitment and work engagements, which contained mediating effect and moderating effect.

\section{Research Model and Hypotheses Development}

\subsection{Perception of Organizational Politics and Work Engagements}

In our research, we preferred adopting definition of perception of organizational politics from Ferris, G. et al. (2000). They defined perception of organizational politics as a subjective evaluation of degree of self-serving behavior of organization members in the working environment. Usually, perception of organizational politics is divided into three dimensions, including general political behavior, going along to get ahead, pay and promotion policies [17]. General political behavior is employees' pursuit for self-interest according to their own needs when the organization lacked clear rules of conduct. Going along to get ahead means that avoiding being involved in organizational politics so as to acquire results beneficial to employees themselves. Pay and promotion policies reflect how organizational policies led to organizational politics.

Schaufeli, B. et al. (2002) defined work engagements as a positive and enjoyable psychological state related to work, which was also a persistent and pervasive emotional cognitive state. Its main features included vigor, dedication and absorption [18]. We did the analysis from the three dimensions of perception of organizational politics. Firstly, if employees perceive general political behavior, it is likely that forming cliques and factions has already existed in organization, which would be a threatening political behavior and led to psychological stress, like anxiety. As a result, employees are not likely to put into work. Secondly, if employees perceive going along to get ahead, they are convinced that "the outstanding usually bear the brunt of attack". They believe what they should do is just avoid doing something wrong, instead of doing something great. Consequently, they wouldn't work with their total dedication. Thirdly, if employees have a perception of pay and promotion policies, it means that they think the performance evaluation system is unfair. In response, employees are likely to decrease their work engagements to get a psychological balance. Previous studies also come up with similar conclusions [8] [19] [20]. Based on the analysis above, we put forward the following hypothesis.

Hypothesis 1: Perception of organizational politics is negatively related to employees' work engagements.

\subsection{Perception of Organizational Politics and Organizational Commitment}

Becker (1960) took the lead to put out organizational commitment theory that organization commitment was based on the economic benefit on both sides. He thought with working in a same organization longer and longer and considering the contribution he made to organization, people usually were not willing to leave their organization. They were scared of losing what they get from the organization now, which made them had to stay on [21]. Meyer and Allen defined organizational commitment as an emotional connection, which contained employees' dependence on the organization and responsibility to organization [22]. Miller, B. K. et al. (2008) dis- 
covered the strong negative relationship between perception of organizational politics and job satisfaction and between perception of organizational politics and organizational commitment by Meta-analysis [10]. In an environment employees perceived organizational politics, their dependence on the organization and responsibility to organization were likely to be destroyed by the organizational politics they perceived. Thus, perception of organizational politics may harm employees’ organizational commitment.

We also did the analysis from the three dimensions of perception of organizational politics. Firstly, if employees perceive general political behavior, it reflects that they realized some threatening behaviors are implemented in their organization, suppressing and bullying, for instance. So their emotional relationship with organization will be damaged. Secondly, if employees perceive going along to get ahead, they are aware that the organization is hierarchical and seniority-based. In that case, they believe in the unwritten rules that a person of high position is liable to be attacked. As a result, they have to choose to remain low-key to avoid making mistakes. And the psychological burden jeopardizes their dependence on the organization and responsibility to organization. In other words, perception of organizational politics would result in the reduction of organizational commitment. Thirdly, they are aware of unfairness among the compensation system and promotion system, which, in their opinion, fail to reflect their contribution to organization truly. Undoubtedly, they feel dissatisfied and lose faith in organization and finally they became less committed to the organizations to which they belonged. Previous research, including some conducted in China, also have similar conclusions [23]-[25]. Based on the analysis above, we put forward the following hypothesis.

Hypothesis 2: Perception of organizational politics is negatively related to employees' organizational commitment.

\subsection{The Mediating Role of Organizational Commitment}

Hobfoll (1989) put forward Conservation of Resources theory to describe the process of resource interaction between individual and social environment. The core of the theory was that individuals with more resources were not vulnerable to the loss of resources, and they had more ability to obtain resources and vice versa [26]. According to the Conservation of Resources theory, if people perceive organizational politics, they need to spend time and energy to deal with their anxiety and nerves, which lead to the loss of their psychological resources. Actually, organizational commitment can be regarded as one of these psychological resources. Balu (1964) thought that people would forecast their returns from the other people by their payment for the other people. Homans (1974) put forward Social Exchange theory and pointed out that the essence of the relationship among people was social exchange, including exchange of material and immaterial. With the reduction of organizational commitment, we could infer that employees' work engagements would also decrease according to Social Exchange theory. For example, when a staff comes up with a new sharp idea, he is going to share his idea with his boss and coworkers. But if the atmosphere is filled with bureaucracies and suppression, he is not likely to share his good idea. Worse still, he might lose his faith in the organization and fail to concentrate on work because he must be constantly alert to the unwritten rules. Hee, J. et al. (2015) found that a higher level of organizational commitment brought a lower level of turnover intention [27]. To date, most of researches have proved that organizational commitment was positively related to employees' work engagements [28]. Based on the analysis above, we put forward the following hypothesis.

Hypothesis 3: Organizational Commitment is positively related to employees' work engagements.

In the practice of research, organizational commitment is also widely used as mediating role to explore the workplace behavior. It was proved that affective commitment and perceived sacrifice commitment played a fully mediated role between pay satisfaction and turnover intention [29]. Pang, J. (2013) found that organizational commitment played a mediating role between perception of corporate social responsibility and job involvement [30]. Chang, Y. et al. (2010) found that organizational commitment played a mediating role between personorganization culture fit and work performance [31]. Bai, G. et al. (2011) found that organizational commitment played a mediating role between career plateau and turnover intention [32]. Zhang, B. (2013) found that organizational commitment played a mediating role between perception of organizational politics and counterproductive work behavior [33]. Peng, W. (2013) found that organizational commitment played a mediating role between perceptions of organizational politics and job performance [34]. Louise, T. (2013) et al. revealed that mediation effect of organizational commitment between emotional exhaustion and job performance [35]. Based on the analysis above, we put forward the following hypothesis. 
Hypothesis 4: Organizational Commitment played a mediating role in the correlation between perceptions of organizational politics and employees’ work engagements.

\subsection{The Moderating Role of Perceived Organization Support}

The theory of perceived organization support was established based on Social Exchange theory, Performance-Reward Expectancy, Personification of Organization [36]-[38]. On this basis, Eisenberger, R. et al. (1986) put forward a definition of perceived organization support that perceived organization support was employees' overall perception and belief how the organization treated their contribution and care for their benefits. And employees' perceived organization support was affected by the way the organization treated them that would promote them choose which behavior to carry out [39]. Rhoades, L. and Eisenberger, R. (2002) found that employees' perceived organization support had an impact on their explanation of organization's motivation [40]. Robert, R. et al. (2009) did a research by means of Meta-analysis and discovered that perceived organization support could strongly forecast job satisfaction [41].

Whether the employees believed the compensation, benefits and promotion were fair would influence their perceived organization support [42]. Yang, F. and Zhang, L. (2012) found that organizational justice positively affected perceived organization support [43]. Vandenberghe and Stinglhamber (2003) found that perceived organization support increased employees' organizational commitment by improving their sense of responsibility, perception of affiliation and helpfulness [44]. Cevat Celep and Ozge Eler Yilmazturk (2012) did a research among teachers working in public primary schools and found that there was a positive relationship between teachers' perceived organizational support and their organizational commitment [45]. Talat, I. et al. (2013) found that perceived organization support positively affected affective commitment and normative commitment [46].

As our previous inference, we thought while employees got perceptions of organizational politics, their organizational commitment would suffer from destroy. But this negative correlation was likely to be weakened to those with high perceived organization support. Because perceived organization support encouraged employees to develop cooperation, which could establish trust relationships among organization. Moreover, perceived organization support made them feel to be valued [40]. Hence, we speculate that the negative correlation between perceptions of organizational politics and organizational commitment would recede with a high perceived organization support.

Perceived organization support was also regarded as a moderating variable in the past research. Gao, Z. et al. (2012) proved that perceived organization support played a moderating role in the correlation between psychological capital and role stress [47]. Li, L. (2013) found that perceived organization support played a moderating role in the relationship between person-organization values fit and career success of female high-level person [48]. Chang, C. (2015) discovered nurses' organizational support perception played a regulating effect on the relationship between their job satisfaction and organizational commitment, which indicated the correlation would be stronger for those with higher organizational support perception [49]. Based on the analysis above, we put forward the following hypothesis.

Hypothesis 5: Perceived organization support played a moderating role in the correlation between perceptions of organizational politics and employees' organizational commitment in such a way that the correlation would be weakened for those with higher perceived organization support.

\section{The Framework for Research}

On the basis of the analysis above, we established the researching framework among perception of organizational politics, perceived organization support, organizational commitment and work engagement. We put forward five hypothesizes and summarized as follow: 1) Perception of organizational politics is negatively related to employees' work engagements; 2) Perception of organizational politics is negatively related to employees' organizational commitment; 3) Organizational commitment is positively related to employees' work engagements; 4) Organizational commitment played a mediating role in the correlation between perceptions of organizational politics and employees' work engagements; 5) Perceived organization support played a moderating role in the correlation between perceptions of organizational politics and employees' organizational commitment in such a way that the correlation would be weakened for those with higher perceived organization support. The frame diagram of our research was showed in Figure 1. 




Figure 1. The researching framework among perception of organizational politics, perceived organization support, organizational commitment and work engagement.

\section{Conclusion}

Organizational politics is common phenomena, which has been proved to bring about negative job attitudes and workplace behaviors. On the one hand, so far most of the researches are based on the western cultural background. Whether the results will be available in other cultural background needs further investigations. On the other hand, researches on organizational politics are still at the beginning stage in China, while that in Western countries has achieved considerable results. In this context, we carry out our research by literature analysis and the result indicates that the perception of organizational politics is negatively related to employees' work engagements, in which organizational commitment plays a mediating role and perceived organization support plays a regulating role. Moreover, perceived organization support regulates the negative correlation between the perception of organizational politics and organizational commitment in such a way that the negative correlation will be weakened for those with higher perceived organization support. Furthermore, if the hypothesizes we put forward are correct, Chinese enterprises should manage to reduce the frequency and strength of organizational politics. As analyzed above, we think that the perception of organizational politics will harm employees' work engagements by decreasing their organizational commitment. For one thing, the enterprises should take effective measures to decrease organizational politics. Meanwhile, the management should evaluate results of organizational politics by implementing new policies, like designing compensation system and promotion system. For another, while organizational politics is inevitable, the enterprises should provide more support to employees and care more about their benefits to minimize the negative correlation between the perception of organizational politics and work engagements. In the end, the limitation of our research is that we adopt theoretical research method without empirical research method, and we will implement that in the subsequent research.

\section{References}

[1] Burns, T. (1961) Micro Politics: Mechanisms of Institutional Change. Administrative Science Quarterly, 6, $257-281$. http://dx.doi.org/10.2307/2390703

[2] Mayes, B.T. and Allen, R.W. (1977) Toward a Definition of Organizational Polities. The Academy of Management Review, 2, 672-675.

[3] Kotter, J.R. (1985) Power and Influence: Beyond Formal Authority. Free Press, New York.

[4] Lewin, K. (1936) Principles of Topological. McGraw-Hill, New York. http://dx.doi.org/10.1037/10019-000

[5] Ferris. G.R. and Kacmar, K.M. (1992) Perceptions of Organizational Politics. Journal of Management, 18, 93-116. http://dx.doi.org/10.1177/014920639201800107

[6] Hochwarter, W.A., Witt, L.A. and Kacmar, K.M. (2000) Perceptions of Organizational Politics as a Moderator of Relationship between Conscientiousness and Job Performance. Journal of Applied Psychology, 85, 472-478. http://dx.doi.org/10.1037/0021-9010.85.3.472

[7] Ferris, G., Harrell-Cook, G. and Dulebohn, J.H. (2000) Organizational Politics: The Nature of the Relationship between Politics Perceptions and Political Behavior. Research in the Sociology of Organizations, 17, 89-103. http://dx.doi.org/10.1016/S0733-558X(00)17004-1 
[8] Corpanzano, R., Howes, J.C., Grandey, A.A. and Toth, P. (1997) The Relationship of Organizational Politics and Support to Work Behaviors, Attitudes, and Stress. Journal of Organizational Behavior, 18, 159-180. http://dx.doi.org/10.1002/(SICI)1099-1379(199703)18:2<159::AID-JOB795>3.0.CO;2-D

[9] Poon, J.M. (2003) Situational Antecedents and Outcomes of Organizational Politics Perceptions. Journal of Managerial Psychology, 18, 138-155. http://dx.doi.org/10.1108/02683940310465036

[10] Miller, B.K., Rutherford, M.A. and Kolodinsky, R.W. (2008) Perceptions of Organizational Politics: A Meta-Analysis of Outcomes. Journal of Business and Psychology, 22, 209-222. http://dx.doi.org/10.1007/s10869-008-9061-5

[11] Hochwarter, W.A. and Thompson. K.R. (2010) The Moderating Role of Optimism on Politics-Outcomes Relationships: A Test of Competing Perspectives. Human Relations, 63, 1371-1394. http://dx.doi.org/10.1177/0018726709357250

[12] Karatepe, O.M. (2013) Perceptions of Organizational Politics and Hotel Employee Outcomes: The Mediating Role of Work Engagement. International Journal of Contemporary Hospitality Management, 25, 82-104. http://dx.doi.org/10.1108/09596111311290237

[13] Zhang, G.J. and Lee, G. (2010) The Moderation Effects of Perceptions of Organizational Politics on the Relationship between Work Stress and Turnover Intention: An Empirical Study about Civilian in Skeleton Government of China. iBusiness, 2, 268-273. http://dx.doi.org/10.4236/ib.2010.23034

[14] Hsiung, H.H., Lin, C.W. and Lin, C.S. (2012) Nourishing or Suppressing? The Contradictory Influences of Perception of Organizational Politics on Organizational Citizenship Behavior. Journal of Occupational and Organizational Psychology, 85, 258-276. http://dx.doi.org/10.1111/j.2044-8325.2011.02030.x

[15] Hofstede, G. (1980) Culture’s Consequences: International Differences in Work Related Values. Sage, London.

[16] Chang, C.H., Rosen, C.C. and Levy, P.E. (2009) The Relationship between Perceptions of Organizational Politics and Employee Attitudes, Strain, and Behavior: A Meta-Analytic Examination. Academy of Management Journal, 52, 779801. http://dx.doi.org/10.5465/AMJ.2009.43670894

[17] Kacmar, K.M. and Ferris, G.R. (1991) Perceptions of Organizational Politics Scale (POPS): Development and Construct Validation. Educational and Psychological Measurement, 51, 193-205. http://dx.doi.org/10.1177/0013164491511019

[18] Schaufeli, W.B., Salanova, M., González-Romá, V. and Bakker, A.B. (2002) The Measurement of Engagement and Burnout: A Two Sample Confirmatory Factor Analytic Approach. Journal of Happiness Studies, 3, 71-92. http://dx.doi.org/10.1023/A:1015630930326

[19] Wang, B. (2013) The Study on the Influence of Perceived Organizational Politics on Job Involvement: Perceived Organizational Support as a Mediator. Zhejiang Sci-Tech University, Hangzhou.

[20] Wang, Y. (2013) Empirical Research on the Relationship of Perceptions of Organizational Politics, Perceived Job Insecurity and Job Involvement. Southwestern University of Finance and Economics, Chengdu.

[21] Becker, H.S. (1960) Notes on the Concept of Commitment. American Journal of Sociology, 66, 32-42. http://dx.doi.org/10.1086/222820

[22] Meyer, J.P. and Allen, N.J. (1991) A Three-Component Conceptualization of Organizational Commitment. Human Resource Management Review, 1, 61-89. http://dx.doi.org/10.1016/1053-4822(91)90011-Z

[23] Vigoda, E. (2000) Organizational Politics, Job Attitudes, and Work Outcomes: Exploration and Implications for the Public Sector. Journal of Vocational Behavior, 57, 326-347. http://dx.doi.org/10.1006/jvbe.1999.1742

[24] Vigoda-Gadot, E., Vinarski-Peretz, H. and Ben Zion, E. (2003) Polities and Image in the Organizational Landscape: An Empirical Examination among Public Sector Employees. Journal of Managerial Psychology, 18, 764-787.

[25] Peng, W. (2013) Study on the Relationship between Perceptions of Organizational Politics, Organizational Commitment and Job Performance. Central South University, Changsha.

[26] Hobfoll, S.E. (1989) Conservation of Resources-A New Attempt at Conceptualizing Stress. American Psychologist, 44, 513-524. http://dx.doi.org/10.1037/0003-066X.44.3.513

[27] Kang, H.J.A., Gatling, A. and Kim, J.S. (2015) The Impact of Supervisory Support on Organizational Commitment, Career Satisfaction, and Turnover Intention for Hospitality Frontline Employees. Journal of Human Resources in Hospitality \& Tourism, 14, 68-89. http://dx.doi.org/10.1080/15332845.2014.904176

[28] Demerouti, E., Bakker, A.B., de Jonge, J., Janssen, P.P.M. and Schaufeli, W.B. (2001) Burnout and Engagement at Work as a Function of Control. Scandinavian Journal of Work Environment and Health, 27, 279-286. http://dx.doi.org/10.5271/sjweh.615

[29] Vandenberghe, C. and Tremblay, M. (2008) The Role of Pay Satisfaction and Organizational Commitment in Turnover Intentions: A Two-Sample Study. Journal of Business and Psychology, 22, 275-286. http://dx.doi.org/10.1007/s10869-008-9063-3

[30] Pang, J. (2013) The Research on the Relationship among Employees’ Perception of Corporate Social Responsibility, 
Organizational Commitment and Job Involvement. Jilin University, Changchun.

[31] Chang, Y.P., Zheng, Y., Zhu, D.H. and Yan, J. (2010) A Study on Relationship between Person-Organization Culture Fit and Work Performance. Chinese Journal of Management, 7, 373-378.

[32] Bai, G.L., Ling, W.Q. and Li, G.H. (2011) Research on Relationship between Career Plateau and Job Satisfaction, Organizational Commitment and Turnover Intention. Soft Science, 2, 108-111.

[33] Zhang, B. (2013) A Empirical Research on Relationship among Employees’ Perception of Organizational Politics, Organizational Commitment and Counterproductive Work Behavior. Nanjing Normal University, Nanjing.

[34] Peng, W. (2013) Study on the Relationship between Perceptions of Organizational Politics, Organizational Commitment and Job Performance. Central South University, Changsha.

[35] Tourigny, L., Baba, V.V., Han, J. and Wang, X.Y. (2013) Emotional Exhaustion and Job Performance: The Mediating Role of Organizational Commitment. The International Journal of Human Resource Management, 24, 514-532. http://dx.doi.org/10.1080/09585192.2012.694109

[36] Gouldner, H.P. (1960) Dimension of Organizational Commitment. Administrative Science Quarterly, 4, 468-490.

[37] Blau. P.M. (1964) Exchange and Power in Social Life. Wiley, New York.

[38] Levinson, H. (1965) Reciprocation: The Relation between Man and Organization. Administrative Science Quarterly, 9, 400-415. http://dx.doi.org/10.2307/2391032

[39] Eisenberger, R., Huntington, R., Hutchison. S. and Sowa, D. (1986) Perceived Organizational Support. Journal of Applied Psychology, 71, 500-507. http://dx.doi.org/10.1037/0021-9010.71.3.500

[40] Rhoades, L. and Eisenberger, R. (2002) Perceived Organizational Support: A Review of the Literature. Journal of Applied Psychology, 87, 698-714. http://dx.doi.org/10.1037/0021-9010.87.4.698

[41] Riggle, R.J., Edmondson, D.R. and Hansen, J.D. (2009) A Meta-Analysis of the Relationship between Perceived Organizational Support and Job Outcomes: 20 Years of Research. Journal of Business Research, 62, 1027-1030. http://dx.doi.org/10.1016/j.jbusres.2008.05.003

[42] Shore, L.M. and Shore, T.H. (2004) Perceived Organizational Support and Organizational Justice. In: Cropanzano, R.S. and Kacmar, K.M., Eds., Organizational Politics, Justice and Support: Managing the Social Climate of the Workplace, Vol. 68, Quorum Books, Westport, 234-356.

[43] Yang, F. and Zhang, L.H. (2012) Organizational Justice and Perceived Organizational Support: The Moderating Role of Conscientiousness in China. Nankai Business Review International, 3, 145-166. http://dx.doi.org/10.1108/20408741211244398

[44] Stinglhamber, F. and Vandenberghe, C. (2003) Organizations and Supervisors as Sources of Support and Targets of Commitment: A Longitudinal Study. Journal of Organizational Behavior, 24, 251-270. http://dx.doi.org/10.1002/job.192

[45] Celep, C. and Yilmazturk, O.E. (2012) The Relationship among Organizational Trust, Multidimensional Organizational Commitment and Perceived Organizational Support in Educational Organizations. Procedia-Social and Behavioral Sciences, 46, 5763-5776. http://dx.doi.org/10.1016/j.sbspro.2012.06.512

[46] Islam, T., Khan, S.R., Ahmad, U.N.B.U., Ali, G., Ahmed, I. and Bowra, Z.A. (2013) Turnover Intentions: The Influence of Perceived Organizational Support and Organizational Commitment. Procedia-Social and Behavioral Sciences, 103, 1238-1242.

[47] Gao, Z.H., Zhao, C., Li, C.P., Wu, C.B. and Hong, R.L. (2012) The Influence Mechanism of Psychological Capital on Turnover Intention: A Moderated Mediation Model Based on Resource Conservation Theory. China Soft Science, 3, 138-148.

[48] Li, L. (2013) A Study on Relationships between Person-Organization Values Fit and Career Success of Female HighLevel Person: Perceived Organizational Support as a Moderator Factor. Jilin University, Changchun.

[49] Chang, C.-S. (2015) Moderating Effects of Nurses’ Organizational Support on the Relationship between Job Satisfaction and Organizational Commitment. Western Journal of Nursing Research, 37, 724-745. http://dx.doi.org/10.1177/0193945914530047 